Research Article

\title{
Group B streptococcal meningitis in the first year of life: a nationwide surveillance study in cuba, 1998 2016
}

\begin{abstract}
Background: Group B streptococcus is a frequent cause of sepsis and neonatal death. The objective of the present study is to characterize the behavior of Group B streptococcal meningitis in Cuban infants.
\end{abstract}

Methods: A 19 years lasting retrospective observational study of 82 cases of Group B streptococcal meningitis was carried out (January 1st, 1998-December 31st, 2016). Risk was estimated annually, by age and gender, as well as case-fatality rate and the association of delay in medical consultation and hospitalization with death

Results: Overall incidence was $0.03 / 1000$ live births, mortality rate $0.01 / 1000$ live births and case-fatality rate of $28.05 \%$. Sex ratio reached 1 . Infants younger than one month represented the largest proportion $(65.85 \%)$ of cases, accounting the majority of deceased (14) with case-fatality rate of $25.93 \%$. Early onset of disease occurred in 3 cases, late onset in 18 cases and 28 presented young infant disease. No deaths reported among cases with early onset of disease, but in late onset and infant disease occurred $14(27.45 \%)$ and nine young infant disease (32.14\%) respectively. Around a quarter of cases share dormitories with $\geq 4$ individuals. The overall mean time for consultation and hospital admittance was lower than 24 hours. Weak $(R R=1.310 .03-8.70$ CI95 \%, $<<0.05$ in cases with late onset of disease) or no association of delay in medical consultation and hospital admittance with death was demonstrated.

Conclusion: GBS meningitis still persists as an important and preventable cause of meningitis and neonatal and infant mortality in Cuba. Monitoring and detection of changes in the behavior of these infections has been demonstrated necessary and useful for prevention and control of these life-threatening infections.

Keywords: streptococcus agalactiae, group b streptococcus, epidemiology, meningitis, infants, neonates
Volume 7 Issue 3 - 2017

\section{Felix Orlando Dickinson Meneses, Misladys Rodriguez Ortega, Yohana Salazar Alvarez, Elba Cruz Rodriguez}

Department of Epidemiology, Tropical Medicine Institute Pedro Kouri, Cuba

Correspondence: Felix Orlando Dickinson Meneses PhD, Department of Epidemiology, Tropical Medicine Institute Pedro Kourí, Autopista Novia del Mediodía, km. 6, municipio La Lisa. Havana, Cuba,Tel 53-7-25532I I,Email dickinson@ipk.sld.cu

Received: October 27, 2017 | Published: November 27, 2017
Abbreviations: BMNSS, bacterial meningitis national surveillance system; CFR, case-fatality rate; EOD, early-onset disease; GBS, Group B streptococcus; HIV, human immunodeficiency virus; LOD, late-onset disease; NPPCINS, national program for the prevention and control of infectious neurological syndromes; RR, relative risk; YID, young infant disease

\section{Introduction}

Streptococcus agalactiae, also referred as group B streptococcus (GBS), is the most common etiologic agent of neonatal sepsis and is associated with high rates of mortality and morbidity. ${ }^{1,2}$

Neonatal and young infant GBS disease can be classified into earlyonset disease (EOD, onset during the first 6 days of life), and lateonset disease (LOD, onset between days 7-89 of life). It is estimated that $60.00-90.00 \%$ of EOD occurs on the first day of life. ${ }^{3,4}$ In the first week of life, invasive disease may appear early and frequently can cause bacteremia or pneumonia. After this period, transmission can be associated with medical care or community. ${ }^{5}$ In most cases, it can manifests clinically as bacteremia, but also as meningitis. Both clinical forms can cause high case-fatality rate (CFR), causing often severe permanent neurological sequel. ${ }^{6}$

The epidemiology of GBS disease considerably varies geographically and over time. A recent meta-analysis of worldwide published studies reported a mean global incidence of $0.53 / 1000$ live births and a mean CFR of $9.60 \% .^{7}$
GBS is a Gram-positive bacterium, and there are 10 serotypes based on their capsular polysaccharide composition (Ia, Ib, II-IX). The polysaccharide capsule is a major virulence factor contributing to bacterial evasion of phagocytic clearance. ${ }^{8}$ Serotype III is the most common invasive isolates and accounts for $30.00-50.00 \%$ of EOD and majority of LOD. ${ }^{7,9}$ The bacteria colonize the human vagina, upper gastrointestinal and respiratory tract of healthy humans. The entrance door is often not obvious, but may be through the skin, genital, urinary and respiratory tract. Vertical transmission (mother to child) from colonized mothers can lead to invasive disease in their offspring. Later on, it transmission can also occurs horizontally, and its origin can be associated with medical care or community. ${ }^{5}$ Disease in neonates and young infants develops as a result of bacterial invasion across epithelial cells into the bloodstream. ${ }^{10}$ HIV-exposed infants are at a higher risk of developing invasive GBS disease. ${ }^{3,11}$

GBS infections are strongly associated with preterm birth (especially very low birth weight), premature and prolonged time of membranes rupture ( $>18$ hours), alterations of the innate immune response, male gender, low neonatal Apgar scoring, wet lung, fetal distress, anemia, hypothermia, and metabolic disorders, maternal peripartum infection, and low socioeconomic status. ${ }^{12}$

In the available Cuban medical literature, GBS infections have been scarcely discussed; most of the articles published on this topic are limited case studies at Pediatrics Hospitals. This article describes behavior of disease in infants based on Bacterial Meningitis National 
Surveillance System (BMNSS) data, aiming to increase awareness and knowledge about these severe infections in the Cuban context, allowing a better control and prevention.

\section{Methods}

This retrospective observational study includes 82 confirmed cases of GBS meningitis in infants between January $1^{\text {st }}, 1998$ and December $31^{\text {st }}, 2016$. The research was based on information obtained from the BMNSS questionnaires as part of the National Program for the Prevention and Control of Infectious Neurological Syndromes (NPPCINS $)^{13}$ of the Republic of Cuba Public Health Ministry.

The questionnaires provide uniform and truthful information throughout the country, ${ }^{14}$ allowing to consolidate a database for further analysis and interpretation. Incidence and mortality by age (years old, months old and days old), gender, year, were calculated (cases or deaths/1000 live births) using the Cuban population estimates of the National Bureau of Statistics. CFR also was calculated as the proportion of fatality among cases.

It was considered a case of GBS meningitis "a clinical meningeal syndrome, through the identification of the GBS directly by culture blood, cerebrospinal fluid analysis or indirectly by polymerase chain reaction or another rapid diagnostic test".

For the purpose of this study, three groups were defined according the onset of disease: EOD: $<7$ days old, LOD: 7-28 days old and young infant disease (YID): $\geq 29$ days old.

Bivariate analysis was used to elucidate related factors to mortality, comparing deaths versus survival. For the assessment of the delay in the medical attention and hospitalization we defined delay in medical consultation "when the time elapsed between the symptoms onset and the initial medical consultation was $\geq 24$ hours" and delayed hospital admittance as "the time elapsed between the first medical consultation and hospitalization was $\geq 24$ hours". Relative Risk (RR) was estimated and its confidence interval (95\%) with $\mathrm{p}<0.05$ considered as significant, using either a Chi-squared Test or Fisher's Exact Test as appropriate. We considered exposed those who reach medical consultation or hospital admission was $\geq 24$ hours), and non-exposed those who reach the medical consultation or hospital admission within $<24$ hours.

The present research was approved by the Scientific Board of the Tropical Medicine Institute Pedro Kourí at Havana and does not represent a risk for the participants and the benefits obtained, justified its realization in a bioethical context. The research did not require approval from an Ethics Committee, considering the Cuban Ministry of Public Health as the governmental organization responsible for the collection of infectious disease notifications, hospital discharge records and population or laboratory surveillance. The management of these data for public health purposes does not require a patient's informed consent nor does it require any authorization regarding privacy laws in Cuba.

\section{Results}

From January 1998 to December 2016, it was notified country wide 1144 bacterial meningitis cases in children $<1$ year old. Among them, 82 were caused by GBS $(7.16 \%)$, with an annual average of four cases. The number of GBS meningitis cases remained stable along the study period, with the exception of 2003 (8 cases), 1999 and 2013 (6 cases each), resulting the years with higher figures. The incidence of the period was $0.03 / 1000$ live births with the highest numbers in 2003 (0.06/live births), and 2013 (0.05/live births). The lowest annual rate was $0.02 /$ live births (years 2000, 2001, 2004, 2006, 2012, 2015, and 2016) (Table 1).

Table I Cases, deaths, incidence, mortality and case-fatality rate of infants with Group B streptococcal meningitis. Cuba, 1998-2016

\begin{tabular}{llllll}
\hline Year & \multicolumn{6}{l}{ Cases } & Deaths & \multicolumn{3}{l}{ Incidence } & Mortality & Case-fatality Rate \\
\hline 1998 & 5 & 1 & 0,03 & 0,01 & 20,00 \\
1999 & 6 & 2 & 0,04 & 0,01 & 33,33 \\
2000 & 3 & 2 & 0,02 & 0,01 & 66,67 \\
2001 & 4 & 1 & 0,02 & 0,01 & 25,00 \\
2002 & 5 & 2 & 0,04 & 0,01 & 40,00 \\
2003 & 8 & 3 & 0,06 & 0,02 & 37,50 \\
2004 & 3 & 1 & 0,02 & 0,01 & 33,33 \\
2005 & 4 & 2 & 0,03 & 0,02 & 50,00 \\
2006 & 2 & 0 & 0,02 & 0,00 & 0,00 \\
2007 & 3 & 0 & 0,03 & 0,00 & 0,00 \\
2008 & 5 & 3 & 0,04 & 0,03 & 60,00 \\
2009 & 5 & 0 & 0,04 & 0,00 & 0,00 \\
2010 & 5 & 2 & 0,04 & 0,02 & 40,00 \\
2011 & 5 & 1 & 0,04 & 0,01 & 20,00 \\
2012 & 3 & 0 & 0,02 & 0,00 & 0,00 \\
2013 & 6 & 1 & 0,05 & 0,01 & 16,67 \\
2014 & 4 & 1 & 0,03 & 0,01 & 25,00 \\
2015 & 3 & 0 & 0,02 & 0,00 & 0,00 \\
2016 & 3 & 1 & 0,02 & 0,01 & 33,33 \\
$1998-2016$ & 82 & 23 & 0,03 & 0,01 & 28,05 \\
\hline
\end{tabular}

Considering the age in months, the biggest number (54 cases) was observed in infants less than one month, also representing the largest proportion $(65.85 \%)$, followed by infants one month of age (18 cases), with $21.95 \%$. Only few cases were reported from two to nine months of age (Table 2). Three cases were younger than seven days and all survived (data not shown).

Table 2 Cases, proportion, deaths and case-fatality rate of infants with Group B streptococcal meningitis by month of age. Cuba, 1998-2016

\begin{tabular}{lllll}
\hline Age (Months) & Cases & $\%$ & Deaths & CFR \\
\hline- I & 54 & 65.85 & 14 & 25.93 \\
I & 18 & 21.95 & 8 & 44.44 \\
2 & 4 & 4.88 & 0 & 0 \\
4 & 2 & 2.44 & 0 & 0 \\
5 & 2 & 2.44 & 0 & 0 \\
6 & $\mathrm{I}$ & 1.22 & 0 & 0 \\
9 & $\mathrm{I}$ & 1.22 & $\mathrm{I}$ & 100 \\
Overall & 82 & 100 & 23 & 28.05 \\
\hline
\end{tabular}

According to the moment of disease onset, it was recorded 3 EOD, 18 LOD and 28 YID. The mean age in infants presenting EOD was three days, while those with LOD reached 18 days and YID cases, two months of age (Table 3 ). The most frequent age at the disease onset for EOD was three days, 22 days for LOD, while in YID was one month (Table 3).

\section{*Months of birth}

Overall, there was a not difference in gender (41/41), although male sex ratio predominated in EOD (2.00) and LOD (1.55), but in YID cases prevailed female (Table 3 ).

Information about number of contacts living in dormitories was obtained from database. A total of 21 cases share dormitories with four or more individuals. Among cases presenting LOD and YID, seven $(13.72 \%)$ and $14(50.00 \%)$ sleep in dormitories with four or more persons respectively (Table 3 ). 
Table 3 Characteristics of infants with Group B streptococcal meningitis according to the moment of disease onset. Cuba, 1998-2016

\begin{tabular}{llll}
\hline Characteristics & EOD $(\mathbf{n}=\mathbf{3})$ & LOD $(\mathbf{n}=\mathbf{5 I})$ YID $(\mathbf{n}=\mathbf{2 8})$ \\
\hline \hline Age (days, mean \pm SD) & $3( \pm I .00)$ & $18( \pm 4.9 \mathrm{I})$ & $2^{*}( \pm 2.09)$ \\
Mode & 3 & 22 & $\mathrm{I}^{*}$ \\
Sex ratio (Male/Female) & 2 & 1.55 & 0.4 \\
Death (CFR \%) & $0(0 \%)$ & $14(27.45 \%)$ & $9(32.14 \%)$ \\
$\geq 4$ person/dormitory & $0(0 \%)$ & $7(13.72 \%)$ & $14(50.00 \%)$ \\
\hline
\end{tabular}

A total of 23 fatalities were accounted during the period, for an annual average of nearly one fatality per year (mortality: $0.01 / 1000$ live births). The highest number of deaths was observed in 2003 and 2008 (three each), with mortality rates of 0.06/1000 live births in 2003 and $0.05 / 1000$ live births in 2013. It was not reported fatalities during 2006, 2007, 2009, 2012 and 2015 (Table 1). Along the period CFR reached $28.05 \%$, with highest annual figures in 2000, 2008 and 2005 (66.67, 60.00 and $50.00 \%$ respectively). The lowest (16.67\%) was reported in 2013 (Table 1).

It were notified 14 fatalities in infants under one month (CFR: $25.93 \%)$ and 8 in infants month of birth (44.44\%). The only case reported in infants 9 months, died causing a $100.00 \%$ CFR (Table 2 ). There was no reported deaths among cases with EOD, but in LOD occurred 14 (CFR $27.45 \%$ ) and nine amid those with YID (32.14 \%).

Information on the date of the symptoms onset, early medical consultation, admission and death was obtained in $93.30 \%$ of the cases. The median time for the medical consultation and the hospital admittance was below 24 hours (Data not shown).

It was not possible to calculate the association of the delay for medical consultation and hospital admittance with death in EOD and YID, due to the absence of fatalities among them. Weak association of delay in hospital admittance with death was demonstrated $(\mathrm{RR}=1.31$ 0.03-8.70 CI95 \%, p <0.05) in LOD. The analysis of the delay of medical consultation with death (LOD and overall) and hospital admittance (LOD) neither evidenced any association (Table $4 \& 5$ ).

Table 4 Association of delay in medical consultation with fatal outcome in infants with Group B streptococcal meningitis. Cuba, 1998-2016

\begin{tabular}{|c|c|c|c|c|c|}
\hline \multicolumn{6}{|c|}{ Late Onset of Disease } \\
\hline & Deaths & Survivors & Total & RR (IC $95 \%)$ & $P$ value \\
\hline Exposed & I & 3 & 4 & \multirow{2}{*}{$0.84(0.01-5.63)$} & \multirow{2}{*}{0.0128} \\
\hline Non exposed & 13 & 33 & 46 & & \\
\hline \multicolumn{6}{|l|}{ All Infants } \\
\hline & Deaths & Survivors & Total & RR (IC $95 \%)$ & $P$ value \\
\hline Exposed & I & 6 & 7 & \multirow{2}{*}{$0.38(0.00-2.36)$} & \multirow{2}{*}{0.688} \\
\hline Non exposed & 21 & 48 & 69 & & \\
\hline
\end{tabular}

Table 5 Association of delay in hospital admittance with fatal outcome in infants with Group B streptococcal meningitis. Cuba, 1998-2016

\begin{tabular}{|c|c|c|c|c|c|}
\hline \multicolumn{6}{|c|}{ Late Onset of Disease } \\
\hline & Deaths & Survivors & Total & RR (IC $95 \%)$ & $P$ value \\
\hline Exposed & 1 & 2 & 3 & 1.31 & 0.0168 \\
\hline Non exposed & 13 & 34 & 47 & $(0.03-8.70)$ & \\
\hline
\end{tabular}

\section{All Infants}

\begin{tabular}{llllll}
\hline & Deaths & Survivors & Total & RR (IC 95 \%) & P value \\
\hline Exposed & I & 3 & 4 & 0.82 & 0.0095 \\
Non exposed & 21 & 52 & 73 & $(0.01-5.13)$ & \\
\hline
\end{tabular}

\section{Discussion}

This paper describes the behavior of GBS meningitis in Cuban infants along 19 years, and is based on data collected from the BMNSS.
No articles have been found in the Cuban bibliography considering the disease from a nationwide perspective. For this reason, the present research might be considered as the first approach to this important health problem in Cuba. It also should contribute to drive the attention of professionals and institutions concerned for the health of children, toward this significant health problem.

There were some potential limitations to be considered and interpreted. First, our study was an observational retrospective design based on questionnaires information, so, it was not expected to explore variables not included in forms (clinical and obstetric information, birth weight, preterm birth). On the other hand, the ability to detect a significant association with mortality might be affected by the available small number of cases. Despite these limitations, we consider the study has important strengths.

First, this report represents one of the largest, longest and deepest epidemiological studies of infant GBS meningitis registered in Cuba so far. Second, it was based on a nationwide surveillance which has been "useful and proficient providing and synthesizing critical and multidisciplinary information, fulfilling all suitable surveillance system attributes" ${ }^{14}$ ensuring reliability of data. Finally, our research includes a geographically well-defined population, with standard nationwide public health system.

It is noteworthy to remark the small number of cases of GBS meningitis reported in Cuba over a prolonged time period, as well as the low incidence observed, resembling figures of high-economic income countries in North America and Europe (0.34-1.90/1000 live birth). ${ }^{6,915-17}$ In sub-Saharan African countries, the incidence may be twice as high, ${ }^{19}$ while the lowest estimates in a global review has been reported in Southeast Asia (0.02/1000 live births). ${ }^{7}$

The largest proportion of cases was observed in infants one month of birth and lower. No publications have been found in Cuba describing the disease according to age in days of birth, but authors in the United States have reported, the mean age for GBS infections around 37 days. ${ }^{16}$ It is likely that the increased frequency of these infections in neonatal period may be related to immaturity of the immune system. Alterations in phagocyte function or humoral immunity factors increase the susceptibility to infections, although the exact nature of these abnormalities and their extent are still not fully understood. ${ }^{18}$

Nearly that $75.00 \%$ of EOD occurs on the first day of life. ${ }^{3,4}$ Data from low and high income countries showed a total EOD incidence of about $0.43 \%$, with the highest values in Africans, followed by Americans and Europeans. Southeast Asia shows the lowest rates of incidence. ${ }^{19}$ In the present research EOD was infrequent compared with LOD and YID, contrarily to results in an extensive surveillance research in $\mathrm{Japan}^{20}$ where EOD accounted near $80.00 \%$. The number of LOD peaked at the age of 18 days, coincident with other authors. ${ }^{20}$ The YID burden was around one third of the total and most cases occur near two month of age. High income countries report less GBS meningitis burden and most cases at 3 months of birth..$^{20-22}$ Low figures of EOD in Cuba might be related with nationwide implementation strategy for the management of vaginal discharge syndrome in pregnant women and their partners, with full and free accessibility to effective drugs in healthcare facilities ${ }^{23}$ and need further confirmation.

GBS meningitis in infants living in crowded dormitories reached more than $60.00 \%$ and affected strictly cases of LOD and YID. Previous studies carried out in Cuba on these infections, point out high frequency of community-acquired origin ${ }^{11}$; therefore, transmission observed during the present research might be also associated mostly 
with community ${ }^{5}$, although future studies to expand and deepen the risk in these environments will be required.

No gender overall differences were found. Prevail of male in EOD and LOD are not coincident with reports in Japan where female is prevalent in all presentations ${ }^{20}$, although in Cuban GBS meningitis YID cases prevailed female.

Case-fatality rate during the study period was high, especially in LOD and YID, exceeding numbers reported previously in hospital based studies in Cuba. ${ }^{24-26}$ This disparity may be due to the national scope of the present study, including all pediatric hospitals in the country. Authors from high-income countries in Southeast Asia, ${ }^{20}$ Europe, ${ }^{27-31}$ United States ${ }^{16}$ and Latin America ${ }^{32,33}$ reported much lower CFR figures.

Although the relationship between mortality and delay in receiving medical care is recognized, ${ }^{33}$ is not clearly defined which are the optimal interval to receive medical care for meningitis patients. Due to severity of these infections, they should receive medical attention the sooner, the better. In a study carried out in Greece during 2009, the mean time between symptoms onset and hospital admission was 42.2 hours. $^{34}$

Some authors have pointed out that the 48-hour delay to initiate treatment in cases of meningitis is significantly associated with an unfavorable outcome. ${ }^{33-35} \mathrm{In}$ the present study, the time elapsed between symptoms onset and medical consultation or hospital admittance was mainly below 24 hours. Therefore, no association with fatality was observed, showing that search for medical care was suitable in most cases. In addition, it should be considered that the characteristics and professional level of public health facilities and proper medical care procedures may contribute significantly to decrease CFR. In Cuba, unlike other countries, the National Health System guarantees free access to optimal medical care, vaccination, and other health services for all citizens. . $^{14,36}$

Despite the success in some countries (including Cuba) ${ }^{24}$ with the use of preventive strategies (intrapartum antibiotic prophylaxis). ${ }^{16,37}$ GBS meningitis continue to be a major health problem, affecting infant mortality and causing severe neurological sequel in the survivors. Other options such as vaccines against the most prevalent serotypes of GBS, has been used in high-income countries. ${ }^{38}$ Immunization of pregnant women with a GBS vaccine represents an alternate pathway to protect newborns from GBS disease, through the transplacental antibody transfer to the fetus in utero. This approach is currently under development to licensure and use in low and middle income country. ${ }^{39-41}$

GBS meningitis still persists as an important and preventable cause of meningitis and neonatal and infant mortality in Cuba. Monitoring and detection of changes in the behavior of these infections has been demonstrated necessary and useful for prevention and control of these life-threatening infections.

\section{Acknowledgments}

We are grateful to all colleagues at national and provincial level of the Bacterial Meningitis Surveillance System and the National Program for the Prevention and Control of Infectious Neurological Syndromes for their interest and effort in collecting and providing important information.

\section{Conflicts of interest}

None.

\section{Funding}

None.

\section{References}

1. Stoll BJ, Hansen NI, Sanchez PJ, et al. Early onset neonatal sepsis: the burden of group B Streptococcal and E. coli disease continues. Pediatrics. 2011;127(5):817-826.

2. Verani JR, Mc Gee L, Schrag SJ. Prevention of perinatal group B Streptococcal disease-revised guidelines from CDC. Recommendations and Reports. 2010;59(10):1-32.

3. Cutland CL, Schrag SJ, Thigpen MC, et al. Increased risk for group B Streptococcus sepsis in young infants exposed to HIV, Soweto, South Africa, 2004-2008(1). Emerg Infect Dis. 2015; 21(4):638-645.

4. Schuchat A. Epidemiology of group B streptococcal disease in the United States: shifting paradigms. Clin Microbiol Rev. 1998;11(3):497-513.

5. Poyart C, Réglier-Poupet H, Tazi A, et al. Invasive Group B Streptococcal Infections in Infants, France. Emerg Inf Dis. 2008;14(10):1647-1649.

6. Fluegge K, Siedler A, Heinrich B, et al. Incidence and Clinical Presentation of Invasive Neonatal Group B Streptococcal Infections in Germany. Pediatrics. 2006;117(6):1139-1145.

7. Edmond KM, Kortsalioudaki C, Scott S, et al. Group B streptococcal disease in infants aged younger than 3 months: systematic review and meta-analysis. Lancet. 2012;347(9815):547-556.

8. Melin P, Efstratiou A. Group B streptococcal epidemiology and vaccine needs in developed countries. Vaccine. 2013;31(Suppl 4):D31-D42.

9. LinFY, WhitingA, AddersonE, etal. Phylogenetic lineages of invasive and colonizing strains of serotype III group B Streptococci from neonates: a multicenter prospective study. J Clin Microbiol. 2006;44(4):1257-1261.

10. Edwards MS, Nizet V, Baker CJ. Group B streptococcal infections. In: Wilson CB \& Nizet V (Eds.), Remington and Klein's infectious diseases of the fetus and newborn infant. (8th edn), Elsevier Saunders, Philadelphia, USA. 2016. p.411-456.

11. Epalza C, Goetghebuer T, Hainaut M, et al. High incidence of invasive group B streptococcal infections in HIV-exposed uninfected infants. Pediatrics. 2010;126(3):631-638.

12. Cortese F, Scicchitano P, Gesualdo M, et al. Early and Late Infections in Newborns: Where Do We Stand? A Review. Pediatr Neonatol. 2016;57(4):265-273.

13. Quintana I, Sotolongo F, Llop A, et al. National Program for the Prevention and Control of Infectious Neurological Syndromes. MINSAP, Havana, Cuba. 1999.

14. Perez AE, Dickinson FO, Rodriguez M. Community acquired bacterial meningitis in Cuba: a follow up of a decade. BMC Infectious Diseases. 2010;10:130.

15. Levent F, Baker C, Rench MA, et al. Early Outcomes of Group B Streptococcal Meningitis in the 21st Century. Pediatr Infect Dis J. 2010;29(11):1009-1012.

16. Phares CR, Lynfield R, Farley MM, et al. Epidemiology of Invasive Group B Streptococcal Disease in the United States, 1999-2005. JAMA. 2008;299(17):2056-2065.

17. Sinha A, Russell LB, Tomczyk S, et al. Disease burden of group B Streptococcus among infants in sub-Saharan Africa: a systematic literature review and meta-analysis. Pediatr Infect Dis J. 2016; 35(9):933-942.

18. Crespo MP, Velez JD. Clinical importance of Streptococcus agalactiae as a cause of infection. Colomb Med. 1996;27:53-58. 
19. Hood M, Janney A, Dameron G. Beta hemolytic streptococcus group B associated with problems of the perinatal period. Am J Obstet Gynecol. 1961;82:809-818.

20. Matsubara K, Hoshina K, Kondo M, et al. Group B streptococcal disease in infants in the first year of life: a nationwide surveillance study in Japan, 2011-2015. Infection. 2017;45(4):449-458.

21. Hussain SM, Luedtke GS, Baker CJ, et al. Invasive group B streptococcal disease in children beyond early infancy. Pediatr Infect Dis J. 1995;14(4):278-281.

22. Guilbert J, Levy C, Cohen R. Delacourt C, Renolleau S, Flamant C, et al. Late and ultra-late onset StreptococcusB meningitis: clinical and bacteriological data over 6 years in France. Acta Paediatr. 2010;99(1):47-51.

23. Management of vaginal discharge syndrome in pregnant women. Ministry of Public Health. National STI/HIV/IDS Prevention and Control Program, Cuba. 2017.

24. Díaz M, Claver ID, Pérez J. Infecciones por Streptococcus agalactiae en un servicio de neonatología abierto. Rev Cubana Pediatr. 2008;80(4).

25. Díaz M, Fernández MT, Moreno O, et al. Severe bacterial infection in febrile newborns with no signs of focalization. Rev Cubana Pediatr. $1995 ; 67(2)$.

26. Díaz M, Guerra DM, Vega ME, et al. Infection by group B streptococcus in children after the neonatal period. Rev Cubana Pediatr. 2006;78(4).

27. Giannoni E, Berger C, Stocker M, et al. Incidence and outcome of group B streptococcal sepsis in infants in Switzerland. Pediatr Infect Dis J. 2016;35(2):222-224.

28. Joubrel C, Tazi A, Six A, et al. Group B streptococcus neonatal invasive infections, France 2007-2012. Clin Microbiol Infect. 2015;21(10):910-916

29. Heath PT, Balfour G, Weisner AM, et al. Group B streptococcal disease in UK and Irish infants youngerthan 90 days. Lancet. 2004;363(9405):292-294.

30. Berardi A, Lugli L, Baronciani D, et al. Group B streptococcal infections in a northern region of Italy. Pediatrics. 2007;120(3):487-493.
31. Fluegge K, Siedler A, Heinrich B, et al. Incidence and clinical presentation of invasive neonatal group B streptococcal infections in Germany. Pediatrics. 2006;117(6):1139-1145.

32. Woods CJ, Levy CS. Streptococcus Group B Infections. Drugs, Diseases \& Procedures. Medscape, USA. 2009.

33. Dzupova O, Rozsypal H, Prochazka B, et al. Acute bacterial meningitis in adults: Predictors of outcome. Scand J Infect Dis. 2009;41(5):348-354.

34. Karanika M, Vasilopoulou VA, Katsioulis AT, et al. Diagnostic clinical and laboratory findings in response to predetermining bacterial pathogen: data from the Meningitis Registry. 2009;4(7):e6426.

35. Radetsky M. Duration of symptoms and outcome in bacterial meningitis: an analysis of causation and the implications of a delay in diagnosis. Pediatr Infect Dis J. 1992;11(9):694-697.

36. Castro BL, Cuellar R. Indicadores de salud infantil en Cuba. Rev Cubana Pediatr. 2009;81(Suppl): 20-24.

37. Centers for Disease Control and Prevention. Trends in Perinatal Group B Streptococcal Disease-United States, 2000-2006. MMWR. 2009;58(5):109-112.

38. Kumar A, Paoletti LC, Glaser P, et al. Group B Streptococcus: global incidence and vaccine development. Nat Rev Microbiol. 2006;4(12):932-942

39. Cutland CL, Cunnington M, Olugbosi M, et al. Lessons learnt from enrolment and follow up of pregnant women and their infants in clinical trials in South Africa, a low-middle income country. Vaccine. 2015;33(47):6406-6412.

40. White A, Madhi SA. Ethical considerations for designing GBS maternal vaccine efficacy trials in low-middle income countries. Vaccine. 2015;33(47):6396-6400.

41. Divala TH, Mungwira RG, Laufer MK. Moving targets: The challenges of studying infectious diseases among pregnant women in resource limited settings. Vaccine. 2015;33(47):6401-6405. 